\title{
Geriatric Mental Health Challenges in India- A Review
}

\author{
Reeta Verma Katiyar ${ }^{1}$, Sharique Ahmad², Maha Waqar Beg3, Tanish Baqar ${ }^{4}$ \\ ${ }^{1}$ Department of Psychology, Era's Lucknow Medical College, Lucknow, Uttar Pradesh, India. \\ 2Department of Pathology, Era's Lucknow Medical College, Lucknow, Uttar Pradesh, India. \\ ${ }^{3}$ Dr. Beg's Child Care, Dalibagh, Lucknow, Uttar Pradesh, India. ${ }^{4}$ Era's Lucknow Medical College \& \\ Hospital, Lucknow, Uttar Pradesh, India.
}

\section{ABSTRACT}

\section{BACKGROUND}

Geriatric mental health issues have yet to receive their due recognition in India. Geriatric mental health is plagued by many challenges that prevent the development and progress of its services. The present article is a narrative review that looks at the various challenges faced by geriatric mental health in India. The article describes different specific and general unique challenges faced by geriatric mental health and discusses in detail the nature of each challenge and what must be done to overcome it. The challenges range from demography of Indian aging to sexual issues in the elderly, geriatric depression, dementia care, and the aging lesbian, gay, bisexual, cross-dressers and transgender community. Old age people face special physical and mental health challenges in routine life which are necessary to be recognized and rehabilitate. Mental health problems are often under identified or overlooked by themselves, health-care professionals and even by family members of older people, and the stigma related to mental illness makes people reluctant to seek help. The prevalence of co-morbid condition of illnesses is a powerful demonstration of the link between physical and mental illnesses. Various issues related to policy and research that challenge geriatric mental health are also discussed in this article. The need to incorporate geriatric mental health into primary health care along with the need to train primary care workers and preventive work aimed at suicide prevention in the elderly is stressed. The article addresses these challenges with the aim of positing before the clinician the various challenges faced by geriatric mental health in India in the current era.

\section{KEY WORDS}

Caregivers, Challenges, Dementia, Elderly Care, Elders, Geriatric Depression, Geriatric Mental Health, Geriatrics, Mental Health, Suicide.
Corresponding Author: Dr. Sharique Ahmad, Department of Pathology, Era's Lucknow Medical College, Lucknow, Uttar Pradesh, India.

E-mail: diagnopath@gmail.com

DOI: $10.14260 / j e m d s / 2020 / 391$

Financial or Other Competing Interests: None.

How to Cite This Article: Katiyar RV, Ahmad S, Beg MW, et al. Geriatric mental health challenges in India- an review. J. Evolution Med. Dent. Sci. 2020;9(23):1787-1794, DOI: $10.14260 /$ jemds/2020/391

Submission 06-11-2019,

Peer Review 14-05-2020,

Acceptance 21-05-2020,

Published 08-06-2020.

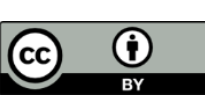




\section{BACKGROUND}

India's demography consists of a geriatric population which will increase in the years ahead. ${ }^{[1]}$ The scope of geriatric mental health differs from other areas of mental health as geriatric populations have unique needs, thereby fostering many challenges.[2] These challenges are seen at every level of care and treatment, from acceptance of a mental health problem to seeking help and remaining compliant in treatment. [3] Lack of trained professionals, scarce geriatric mental health infrastructure, and dearth of financial resources for geriatric mental health are some of the challenges that our nation faces.[4] Geriatric mental health problems can be accurately diagnosed and effectively treated if help is sought early, but it is erroneously assumed that they are part of "normal aging."[5] The unprecedented pace of demographic aging makes geriatric mental health a huge public health challenge for India.[6] The current review discusses the general and specific challenges for geriatric mental health in India from a clinical perspective while proposing some solutions to help encounter these challenges.

\section{GENERAL CHALLENGES FOR GERIATRIC} MENTAL HEALTH IN INDIA

\section{Challenge 1- Demography of Aging in India}

India has the second largest population of 1.31 billion people.[7] Rapid advances in medicine, public health, nutrition, and sanitation have led to large advances to old age. ${ }^{[8,9]}$ The aging population is $>100$ million, and projections predict a figure of 324 million, i.e., $20 \%$ of the total population, by 2050.[10] Since women in old age are more prone to social insecurity, health problems, and greater emotional/financial insecurities they have shown a preponderance to mental health issues as compared to men.[11,12,13,14] Most of the elderly live in rural areas and may be poorly educated thus showing higher association rates of dementia and consequently seem more amongst females. $[15,16]$

\section{Challenge 2- Heterogeneity of Clinical Presentations in Geriatric Mental Health}

A key clinical issue in geriatric mental health is the heterogeneity in clinical presentations that confounds diagnosis and treatment of these problems. In most cases, a clear textbook like clinical picture is absent; patients usually deny the presence of mental health problems and are reluctant to seek help.[17,18] Physical symptoms may be the chief complaint in many cases and the underlying psychological problems are obscured under a garb of physical complaints.[19] Patients differ in the degree of mobility they possess so clinician must understand the same.[20,21] The patient being on multiple medications and multiple doctors treating the patient need to work in synergy for best results.[22]

\section{Challenge 3- Challenge for Dementia Care in India}

Dementia is the most common neuropsychiatric illness besides depression in people above 60 years of age [23] Eight large-scale epidemiological studies have indicated that prevalence for dementia for those aged $>85$ years in India ranges from $18 \%$ to $38 \%$ and, in those $>90$ years, it ranges from $28 \%$ to $44 \%{ }^{[24]}$ While the numbers are expected to be double by 2030 [25] Research suggests that up to $90 \%$ of the time, challenging/psychiatric behaviours that occur in persons who lack the ability to describe and understand their own symptoms with dementia might be caused by either environmental factors or by a caregiver approach. ${ }^{[26,27]}$

\section{Challenge 4- Social Factors that Play a Role in Geriatric Mental Health Problems}

Many factors like social, psychological, and biological factors determine and affect person's level of mental health at any point of time.[28] Apart from all common and typical life stressors, aged people lose their independently living ability, they are more vulnerable to the experience a drop in socioeconomic status with retirement.[29,30] The special social challenges of the elderly population in India are as follows:

1. A majority (80\%) of elderly population are living in the rural areas, thus delivering service is a challenge.[31]

2. The government pension scheme benefits currently only 2.76 million out of 28 million elderly people, especially in urban areas.[32]

3. A large percentage $(30 \%)$ of below the poverty line of elderly.[33]

There are several social factors that subliminally or sometimes, directly, affect the mental health of the geriatric age groups as follows

- Retirement.

- Housing issues.

- Financial issues.

- Lack of transport.

- Parents in India and children abroad.

\section{Challenge 5- Rehabilitation Facilities for Elderly and Interventions in Old Age Homes}

Old age Homes are ideal for elderly people who are alone and face health problems, depression, and loneliness. [34] There are four types of resources available to address geriatric mental health issues in India has, namely

- Psychiatric hospitals and nursing homes funded by state government;

- Private psychiatric clinics or hospitals and nursing homes;

- Nongovernmental organizations (NGOs)

- Informal sources - family as caregivers.[35]

However, various types of early intervention for health and social services are in practice today (and can be accommodated in our country), as follows:

- Community based interventions.

- Outpatient clinics. 
- Domiciliary visits.

- Geriatric day care.

\section{Other Forms of Rehabilitation}

- Residential care and nursing care.

- Hospital care.

- Respite care.

- Home based setups.

These services have been shown to be extremely necessary in India due to following reasons-

1. With the given decrease in family sizes, and the patriarchal society of India, the woman of the family, is forced to take up the sole responsibility to take care of the elderly.[36] Not surprisingly, but larger households have remained associated with lower caregiver strain. ${ }^{[37]}$ Studies show that, even when the responsibility of caring for the elders is taken up willingly, such prolonged care giving frequently leads to a negative impact on the caregivers' emotional and physical health.[38]

2. Due to this increased responsibility of patients suffering from prolonged mental disorders, a greater caregiver strain has been reported with greater patients with greater psychotic symptoms. ${ }^{[39]}$

3. The caregivers are blamed for their behaviour and are often accused with providing inadequate care, adding to the jeopardy of the caregiver.[40] There are minimal community based mental health services that provide aid for the elderly suffering from chronic disorders and almost none that provide support to caregivers. [41] The lack of community based mental health-care services is a challenge for geriatric as mental health hinders adequate care for the elderly and also increases their chance of developing mental disorders. ${ }^{[42]}$

\section{Challenge 6- Lack of Awareness Regarding Geriatric} Mental Health Care at a Primary Care Level

The visiting primary health-care physicians are not trained to identify and treat psychiatric issues such as dementia or depression in elderly, seen in more than $40 \%-50 \%$ of the population. ${ }^{[43]}$ Despite an increase rate in subspecialty geriatric training in various fields the recognition and treatment of geriatric mental illnesses remains uncommon in training.[44] Thus, peripheral health workers and community health volunteers should also be trained to identify and refer elderly patients for timely and proper rehabilitation in order to reach the needy.[45]

Challenge 7- Incorporating Religion and Spirituality into Geriatric Mental Healthcare

Religion and spirituality is an important social and psychological factors in the lives of older adults and there is continued interest in examining the effects of religion and spirituality on health status.[46] Elders with greater religiosity were more likely to report good health status in various studies, and a positive association between organized religiosity and health status has been found.[47] There is a need for psychiatrists being open to discuss the same as well as to respect the religious beliefs of clients that they treat.[48]

\section{Challenge 8- Setting Up Geriatric Mental Health Clinics in India}

In India there are limited number of mental health professionals of around 5000 psychiatrists catering to the 21 million geriatric populations in need of mental health services which exactly not a good ratio.[49] Often, such clinics for geriatric patients are run in hospitals by departments such as neurology, psychiatry, and geriatrics. ${ }^{[50]}$

In the Indian context, there is a dire need for the following-

1. Free or subsidized memory clinics (equipped to diagnose elders with dementia and also educate and provide families with the supportive guidance) for the underprivileged

2. Naming, positioning, and publicity of the clinic should be taken into account

3. People may assume that a memory clinic is only for memory problems

4. The clinic may prepare or procure material required for its functioning, keeping in mind the societal environment and the target audience

5. Modified instruments and procedures for checking cognitive status (such as tests in local languages and tests for illiterate persons)

\section{Challenge 9- Research in Geriatric Psychiatry}

Before delivering any form of relief mechanism to the general elderly population, it needs to be tested.[51,52] There are many barriers for research to be conducted in India, which range from monetary to ethical and permission delivery dilemmas. Primarily, the lack of research can be attributed to the lack of funding from the government to support ongoing research. The Government of India is currently spending

\section{Challenge 10- Lack of Indian Diagnostic Tools}

The pre-existing diagnostic criteria are not designed specifically to assess the mental health status of older people and thus leads to either a misdiagnosis of one's condition or leads to no diagnosis at all, leaving the disorder untreated. Indian criteria keeping in mind the cultural aspects of psychiatric diagnosis are a must. ${ }^{[53,54]}$ findings indicate that dementia in the oldest adults is a result of a DLB phenotype, which is different from that in the younger adults. ${ }^{[55]}$ In sum, the lack of diagnosing criteria and clinical interventions adds to the adversity of geriatric mental health in India.

\section{Challenge 11- Revision of Geriatric Mental Health Policies} The Indian government launched the National Program for the Health Care of the Elderly (NPHCE) in 2011, as an implementation of India's international commitments to the UN Conventions on the Rights of Persons with Disabilities and the National Policy on Older Person as well as its national commitments to the Maintenance and Welfare of Parents And 
Senior Citizens Act, 2007.[56,57] The main aim of NPHCE is "to provide an easy access to promotional, preventive, curative and rehabilitative services through community based primary health-care approach." ${ }^{[58]}$ It is considered extremely important as it recognizes the different, specialized needs of the geriatrics.[59]

\section{Challenge 12- Myths Related to Aging in India}

There are a number of myths about aging. Of note, they are shared by practitioners, patients, and policymakers alike. These are as follows:[60,61]

1. Age is an illness.

2. Disability is inevitable and increasing among seniors.

3. Loss of social ties leaves the older adult alone and isolated.

4. Most elderly are depressed, demented, or dependent.

5. Old age leads to physiologic and social homogeneity.

6. Aging and mortality are synonymous.

\section{Challenge 13- Clinical Challenges Posed by Geriatric Depression}

Depression is undertreated in Geriatric patients as they often have multiple co-existing medical and other psychological problems.[62,63] Older adults are likely to suffer from subsyndromal depression, i.e., depression that does not (always) meet the full criteria for major depression diagnosis but can lead to major depression if left undiagnosed or untreated.[64] According to a WHO report, patients over the age of 55 who suffer from depression have a four times higher death rate than those without depression indicates comparatively higher prevalence of geriatric depression in India, with a median prevalence rate of $21.9 \% .[65,66]$ Studies have identified demographic factors associated with symptoms of geriatric depression which are often ignored by many elderly as a stereotype myth prevails that geriatric depression is normal in old age.[67] Geriatric depression can either be recurrence of a previous depressive episode experienced earlier at younger ages or it be a first episode depression in late life.[68] Depression in older adults is most frequently associated with physiological changes or abnormalities of the brain[69] These changes may also be the result of early changes caused by Alzheimer's disease or vascular dementia in its initial stages.[70]

\section{Challenge 14- Medical Illnesses in the Elderly Affected by Psychological Problems}

It is commonly known that geriatric patients have multiple illnesses, which include both non-cognitive physical and psychiatric illnesses with psychological symptoms.[71] The prevalence of co-morbid condition of illnesses is a powerful demonstration of the link between physical and mental illnesses and the interplay of multiple factors between them. ${ }^{[72]}$ A missed organic cause of psychopathology can lead to significant morbidity and mortality for individuals inappropriately admitted to a psychiatric unit.[73] Nevertheless, it is crucial for medical professionals to have fundamental understanding of psychiatric conditions which will help them in diagnosis as well as in intervention. [74]

\section{Challenge 15- Geriatric Substance Abuse and Its Management}

The prevalence of alcohol consumption among the elderly between the ages of 60 and 64 years was found to be $25.4 \%$. $[75,76]$ Late onset abusers are those who start consumption of alcohol after the age of 65 years in response to negative life events such as retirement and the death of a loved one.[77] These events are extremely common in old age and are further linked to psychological and psychopathological co morbidities, particularly mood and anxiety disorders.[78] Similar to alcohol abuse, it was found that the number of heavy smokers decreased with age, the proportion declined from $22.7 \%$ between the ages of 60 and 64 years to $8.2 \%$ of heavy smokers between the ages of 65 and 75 years.[79] These patients cannot be admitted and treated with adult substance abuse patients as their needs and causative factors differ markedly from that of adult patients with substance abuse. ${ }^{[80]}$

\section{Challenge 16- Management of Delirium in the Elderly}

Delirium is a common medical and psychiatric complication seen in geriatric patients. Most of these patients need Intensive Care Unit admissions [81] Delirium may complicate the clinical picture of dementia and make it difficult to assess clinically due to fluctuating orientation and attention of the patient, might be fatal if ignored[82] Delirium also puts an immense pressure and challenge to the caregivers dealing with the patient on a regular basis. ${ }^{[83]}$

\section{Challenge 17- Sexual Issues in the Elderly}

Sexuality is considered taboo in India with myths like older people are asexual and do not practice or desire sex.[84] On the contrary, the majority of people aged 60 and above continues to engage in and, most importantly, enjoy it. Older adults are often the subjects of humour directed at physical, cognitive, and sexual impotence.[85,86] Some common medical issues encountered in old age such as dementia, visual or hearing impairment erectile dysfunction and medical devices such as catheters affect self-image of the person and impede sexual expression.[87,88,89] Other compounding issues that discourage the older sex by power wielding entities such as residential homes or caregivers, stereotyped media portrayals, lack of acknowledgment of LGBT and queer adults as sexual beings. ${ }^{[90,91]}$

\section{Challenge 18- End-of-Life Care and Cancer in the Elderly} There is a lack of awareness of End Of Life Care (EOLC) for people with chronic, serious, progressive, or advanced life limiting illnesses, including dementia.[92] EOLC involves good communication, clinical decision-making, with medical teams and families, comprehensive assessment, and specialized interventions to meet for physical, psychological, spiritual, and social needs of patients and their caregivers.[93] Relatives, therefore, are often forced to take the patients home on leave against medical advice.[94,95] as per today Cancer and its related problems like depression, anxiety, fatigue is a major public health problem worldwide. Geriatric psycho oncology is still in a nascent state and needs to be enhance and improvise in India.[96,97] 


\section{Challenge 19- Elder Abuse}

Current research evidence suggests that 1 in 10 older people experience elder abuse.[98] The intersection of elder abuse and mental health is important and complex as well and this need to be observed carefully.[99] evidence shows that victims of elder abuse has high prevalence rate of depression, anxiety which paves path to social isolation, increasing the risk of suicide and the emotional devastation. ${ }^{[100]}$ Abuse victims may suffer no of complaints, including, chronic pain, arthritis, neurological complaints, and gynaecological problems.[101] Early deaths are common where elders abuse victims who have other debilitating mental health problems and cannot protect themselves readily.[102] Some of them may manifest multiple physical/somatic complaints without a plausible diagnosis.[103]

Challenge 20- Meeting the Needs of Lesbian, Gay, Bisexual, Transgender, and Queer Elderly

Prior research has indicated that the LGBT populations have a higher incidence of mental health distress, subjected to discrimination, stigmatization, and harassment than the general heterosexual population due to the brutal discriminatory treatment leaves them vulnerable to psychiatric illnesses and psychological distress.[104] A study reported that $9.1 \%$ of elderly lesbian couples and $4.9 \%$ of elderly gay couples were poor, as compared to $4.6 \%$ of their heterosexual couples counterparts.[105] Further, LGBT elderly are twice as more likely to live alone and almost four times less likely to have children than their heterosexual counterparts, poorer physical health of the LGBT elderly also leaves them more vulnerable to mental illnesses.[106,107] Extensive research data does suggest that psychological and psychosocial factors have also an effect on behavior [108] Using mixed methods is a good way of employing triangulation, particularly "methodological triangulation." It will be up to you, the researcher, and your advisor to decide as to which methods will work best for your research questions and goals to decode geriatric psychological issues.[109]

\section{CONCLUSIONS}

The world's population is rapidly aging. Approximately between 2015 and 2050, the proportion of the world's older adults is estimated to double almost from about $12 \%$ to $22 \%$. In absolute terms, this is an expected increase from 900 million to 2 billion people of over 60 of the age. Older people face special physical and mental health challenges which are necessary to be recognized and rehabilitated. Mental health problems are often under-identified or overlooked by health-care professionals and older people themselves, and the stigma related to mental illness makes people reluctant to seek help. Inadequate training opportunities, lack of awareness, virtual absence of chronic care disease models and inequitable distribution of health resources are the common challenges that confound the future of geriatric psychiatry in India. Government policies providing social benefits to the elderly population are in place, but coverage is inadequate and need to be reformed and reframed. For addressing geriatric mental health issues, the need of the hour is strengthening training and research activities, increase awareness, developing community based rehabilitation programs, capacity building, and developing a holistic primary health-care system. There is a need to raise awareness among the public and also professionals about the unmet needs of geriatric mental health, strengthen intersectorial collaboration and develop adequate human resources. There is an urgent need to implement national policies, programs, and legislation targeting geriatric mental health and promoting advocacy and empowerment. Small steps in all directions will go a long way in improving geriatric mental health in India.

\section{REFERENCES}

[1] Magnus G. The age of aging: how demographics are changing the global economy and our world. New York: John Wiley \& Sons 2012.

[2] Patel V, Prince M. Ageing and mental health in a developing country: Who cares? Qualitative studies from Goa, India. Psychol Med 2001;31(1):29-38.

[3] Rait G, Burns A. Appreciating background and culture: The South Asian elderly and mental health. Int J Geriatr Psychiatry 1997;12(10):973-7.

[4] Prince M, Livingston G, Katona C. Mental health care for the elderly in low-income countries: a health systems approach. World Psychiatry 2007;6(1):5-13.

[5] Grover S. Future of psychiatry in India: Geriatric psychiatry, a specialty to watch out for. J Geriatr Ment Health 2014;1(1):1-5.

[6] Bartels SJ, Dums AR, Oxman TE, et al. Evidence-based practices in geriatric mental health care. Psychiatr Serv 2002;53(11):1419-31.

[7] Rao TSS, Shaji KS. Demographic aging: Implications for mental health. Indian J Psychiatry 2007;49(2):78-80.

[8] Prince M, Patel V, Saxena S, et al. No health without mental health. Lancet 2007;370(9590):859-77.

[9] Leveille SG, Guralnik JM, Ferrucci L, et al. Aging successfully until death in old age: opportunities for increasing active life expectancy. Am J Epidemiol 1999;149(7):654-64.

[10] Liebig PS, Rajan SI. An aging India: perspectives, prospects and policies. J Aging Soc Policy 2003;15(23):1-9.

[11] Rajan SI, Sarma PS, Mishra US. Demography of Indian aging, 2001-2051. J Aging Soc Policy 2003;15(23):11-30.

[12] Nygren B, Aléx L, Jonsén E, et al. Resilience, sense of coherence, purpose in life and self-transcendence in relation to perceived physical and mental health among the oldest old. Aging Ment Health 2005;9(4):354-62.

[13] Patel V, Kirkwood BR, Pednekar S, et al. Gender disadvantage and reproductive health risk factors for common mental disorders in women: a community survey in India. Arch Gen Psychiatry 2006;63(4):404-13.

[14] Singh A, Pradhan SK. Menopausal symptoms of postmenopausal women in a rural community of Delhi, India: a cross-sectional study. J Midlife Health 2014;5(2):62-7. 
[15] Chandra V, Ganguli M, Pandav R, et al. Prevalence of Alzheimer's disease and other dementias in rural India: The Indo-US Study. Neurology 1998;51(4):1000-8.

[16] Vedantam A, Subramanian V, Rao NV, et al. Malnutrition in free-living elderly in rural South India: prevalence and risk factors. Public Health Nutr 2010;13(9):1328-32.

[17] O'Sullivan P, Chao S, Russell M, et al. Development and implementation of an objective structured clinical examination to provide formative feedback on communication and interpersonal skills in geriatric training. J Am Geriatr Soc 2008;56(9):1730-5.

[18] Liberman RP, Hilty DM, Drake RE, et al. Requirements for multidisciplinary teamwork in psychiatric rehabilitation. Psychiatr Serv 2001;52(10):1331-42.

[19] Mann RS, Foster JR, Ford CV, et al. A curriculum for education in geriatric psychiatry. Am J Psychiatry 1988;145(7):836-43.

[20] Cohen CI, Vahia I, Reyes P, et al. Focus on geriatric psychiatry: Schizophrenia in later life: clinical symptoms and social well-being. Psychiatr Serv 2008;59(3):232-4.

[21] Pomeroy VM, Warren CM, Honeycombe C, et al. Mobility and dementia: Is physiotherapy treatment during respite care effective? Int J Geriatr Psychiatry 1999;14(5):389-97.

[22] Katon WJ. Clinical and health services relationships between major depression, depressive symptoms and general medical illness. Biol Psychiatry 2003;54(3):216-26.

[23] Das SK, Pal S, Ghosal MK. Dementia: Indian scenario. Neurol India 2012;60(6):618-24.

[24] Kalaria RN, Maestre GE, Arizaga R, et al. Alzheimer's disease and vascular dementia in developing countries: Prevalence, management, and risk factors. Lancet Neurol 2008;7(9):812-26.

[25] Shaji KS, Jotheeswaran AT, Girish N, et al. The Dementia India Report: prevalence, impact, costs and services for dementia. Alzheimer's and Related Disorders Society of India, 2010.

[26] Shaji KS, George RK, Prince MJ, et al. Behavioral symptoms and caregiver burden in dementia. Indian J Psychiatry 2009;51(1):45-9.

[27] Shaji S, Bose S, Kuriakose S. Behavioral and psychological symptoms of dementia: a study of symptomatology. Indian J Psychiatry 2009;51(1):38-41.

[28] Sudha S, Suchindran C, Mutran EJ, et al. Marital status, family ties and self-rated health among elders in South India. J Cross Cult Gerontol 2006;21(3-4):103-20.

[29] Mudey A, Ambekar S, Goyal RC, et al. Assessment of quality of life among rural and urban elderly population of Wardha District, Maharashtra, India. Ethno Med 2011;5(2):89-93.

[30] Kaushal N. How public pension affects elderly labor supply and well-being: evidence from India. World Development 2014;56:214-25.

[31] Chakrabarti S, Sarkar A. Pattern and trend of population ageing in India. Indian J Spat Sci 2011;2:1-5.

[32] Pal S, Palacios R. Understanding poverty among the elderly in India: implications for social pension policy. J Dev Stud 2011;47(7):1017-37.

[33] Reddy NB, Pallavi M, Reddy NN, et al. Psychological morbidity status among the rural geriatric population of
Tamil Nadu, India: a cross-sectional study. Indian J Psychol Med 2012;34(3):227-31.

[34] Kumar SG, Roy G, Kar SS. Disability and rehabilitation services in India: Issues and challenges. J Family Med Prim Care 2012;1(1):69-73.

[35] Murali T, Tibrewala PK. Psychiatric rehabilitation in India. In: Nagaraja D, Murthy, eds. Mental Health Care and Human Rights. New Delhi: National Human Rights Commission 2008: p. 197-204.

[36] Dwyer JW, Coward RT. Gender \& family care of the elderly: Research gaps and opportunities. In: Dwyer JW, Coward RT, eds. Gender, families and elder care. Newbury Park, CA: Sage Publications 1992: p. 3-17.

[37] Bhat AK, Dhruvarajan R. Ageing in India: drifting intergenerational relations, challenges and options. Ageing Society 2001;21(5):621-40.

[38] Shaji KS, Smitha K, Lal KP, et al. Caregivers of people with Alzheimer's disease: a qualitative study from the Indian 10/66 Dementia Research Network. Int J Geriatr Psychiatry 2003;18(1):1-6.

[39] Shankar R, Rao K. From burden to empowerment: The journey of family caregivers in India. Families and Mental Disorders. Chichester, England: John Wiley and Sons Ltd., 2005.

[40] Emmatty LM, Bhatti RS, Mukalel MT. The experience of burden in India: a study of dementia caregivers. Dementia 2006;5:223-32.

[41] Shaji KS, Kishore NRA, Lal KP, et al. Revealing a hidden problem. An evaluation of a community dementia case-finding program from the Indian 10/66 Dementia Research Network. Int J Geriatr Psychiatry 2002;17(3):222-5.

[42] Patel V, Thara R. Meeting the Mental Health Needs of Developing Countries: NGO Innovations in India. New Delhi: Sage Publications India 2003.

[43] Brijnath B, Manderson L. Appropriation and dementia in India. Cult Med Psychiatry 2011;35(4):501-18.

[44] Mccabe LF. The cultural and political context of the lives of people with dementia in Kerala, India. Dementia 2006;5(1):117-36.

[45] Shaji KS, Kishore NRA, Lal KP, et al. Better mental health care for older people in India. Indian J Psychiatry 2004;46(4):367-72.

[46] Thompson S. Reciprocity and dependency in old age: Indian and UK perspectives. New York: Springer Verlag 2013.

[47] Agrawal J, Murthy P, Philip M, et al. Socio-demographic correlates of subjective well-being in urban India. Soc Indicators Res 2011;101(3):419-34.

[48] Tharayil HM, Thomas A, Balan BV, et al. Mental health care of older people: Can the district mental health program of India make a difference? Indian J Psychol Med 2013;35(4):332-4.

[49] Shaji KS, Iype T, Praveenlal K. Dementia clinic in general hospital settings. Indian J Psychiatry 2009;51(1):42-4.

[50] Scholzel-Dorenbos CJM, Meeuwsen EJ, Rikkert MGMO. Integrating unmet needs into dementia health-related quality of life research and care: introduction of the hierarchy model of needs in dementia. Aging Ment Health 2010;14(1):113-9. 
[51] Collins PY, Patel V, Joestl SS, et al. Grand challenges in global mental health. Nature 2011;475(7354):27-30.

[52] Math SB, Srinivasaraju R. Indian psychiatric epidemiological studies: learning from the past. Indian J Psychiatry 2010;52(Suppl 1):S95-S103.

[53] Azermai M, Petrovic M, Elseviers MM, et al. Systematic appraisal of dementia guidelines for the management of behavioural and psychological symptoms. Ageing Res Rev 2012;11(1):78-86.

[54] Taylor D, Paton C, Kapur S. The Maudsley prescribing guidelines in psychiatry. New York: John Wiley and Sons Ltd., 2015.

[55] Vann Jones SA, O’Brien JT. The prevalence and incidence of dementia with Lewy bodies: a systematic review of population and clinical studies. Psychol Med 2014;44(4):673-83.

[56] World Health Organization, World Organization of National Colleges, Academies, Academic Associations of General Practitioners/Family Physicians. Integrating Mental Health into Primary Care: A Global Perspective. Geneva: World Health Organization, 2008.

[57] Murthy RS. Mental health initiatives in India (19472010). The National Medical J of India 2011;24(2):98107.

[58] Singh AP, Shukla A, Singh PA. Perceived self-efficacy and mental health among elderly: a study from India. J Indian Acad Geriatr 2009;5:171-6.

[59] Jeste DV, Alexopoulos GS, Bartels SJ, et al. Consensus statement on the upcoming crisis in geriatric mental health: research agenda for the next 2 decades. Arch Gen Psychiatry 1999;56(9):848-53.

[60] Dykstra PA. Older adult loneliness: myths and realities. Eur J Ageing 2009;6(2):91-100.

[61] Bludau J. Aging, but never old: the realities, myths and misrepresentations of the anti-aging movement. New York: ABC-CLIO 2010.

[62] Jain RK, Aras RY. Depression in geriatric population in urban slums of Mumbai. Indian J Public Health 2007;51(2):112-3.

[63] Grover S, Malhotra N. Geriatric depression: a review of Indian research. J Geriatr Ment Health 2015;2(1):4-15.

[64] Sengupta P, Benjamin AI. Prevalence of depression and associated risk factors among the elderly in urban and rural field practice areas of a tertiary care institution in Ludhiana. Indian J Public Health 2015;59(1):3-8.

[65] Barua A, Ghosh MK, Kar N, et al. Socio-demographic factors of geriatric depression. Indian J Psychol Med 2010;32(2):87-92.

[66] Sharma K, Gupta A, Sharma RC, et al. Prevalence and risk factors for depression in elderly North Indians. J Geriatr Ment Health 2016;3(2):158-63.

[67] Fountoulakis KN, O’Hara R, Iacovides A, et al. Unipolar late-onset depression: a comprehensive review. Ann Gen Hosp Psychiatry 2003;2(1):11.

[68] Fiske A, Wetherell JL, Gatz M. Depression in older adults. Annu Rev Clin Psychol 2009;5:363-89.

[69] Taylor WD, Aizenstein HJ, Alexopoulos GS. The vascular depression hypothesis: Mechanisms linking vascular disease with depression. Mol Psychiatry 2013;18(9):963-74.

[70] Korczyn AD, Halperin I. Depression and dementia. J Neurol Sci 2009;283(1-2):139-42.
[71] Prakash 0, Gupta LN, Singh VB, et al. Profile of psychiatric disorders and life events in medically ill elderly: experiences from geriatric clinic in Northern India. Int J Geriatr Psychiatry 2007;22(11):1101-5.

[72] Lena A, Ashok K, Padma M, et al. Health and social problems of the elderly: a cross-sectional study in Udupi Taluk, Karnataka. Indian J Community Med 2009;34(2):131-4.

[73] Seby K, Chaudhury S, Chakraborty R. Prevalence of psychiatric and physical morbidity in an urban geriatric population. Indian J Psychiatry 2011;53(2):121-7.

[74] Sharma MK, Swami HM, Bhatia V, et al. An epidemiological study of correlates of osteo-arthritis in geriatric population of UT Chandigarh. Indian J Community Med 2007;32(1):77-83.

[75] Murthy P, Manjunatha N, Subodh BN, et al. Substance use and addiction research in India. Indian J Psychiatry 2010;52(Suppl 1):S189-S99.

[76] Benegal V. India: Alcohol and public health. Addiction 2005;100(8):1051-6.

[77] Das SK, Balakrishnan V, Vasudevan DM. Alcohol: its health and social impact in India. Natl Med J India 2006;19(2):94-9.

[78] Blazer DG, Wu LT. The epidemiology of substance use and disorders among middle aged and elderly community adults: National survey on drug use and health. Am J Geriatr Psychiatry 2009;17(3):237-45.

[79] Goswami A, Reddaiah VP, Kapoor SK, et al. Tobacco and alcohol use in rural elderly Indian population. Indian J Psychiatry 2005;47(4):192-7.

[80] Simoni-Wastila L, Yang HK. Psychoactive drug abuse in older adults. Am J Geriatr Pharmacother 2006;4(4):380-94.

[81] Grover S. Delirium - most prevalent disorder: still a clinical orphan. J Geriatr Ment Health 2014;1(2):57-9.

[82] Grover S, Lahariya S, Bagga S, et al. Incidence, prevalence and risk factors for delirium in the elderly admitted to a coronary care unit. J Geriatr Ment Health 2014;1(1):45-53.

[83] Sharma A, Malhotra S, Grover S, et al. Incidence, prevalence, risk factor and outcome of delirium in Intensive Care Unit: a study from India. Gen Hosp Psychiatry 2012;34(6):639-46.

[84] Rao TSS, Ismail S, Darshan MS, et al. Sexual disorders among elderly: an epidemiological study in South Indian rural population. Indian J Psychiatry 2015;57(3):236-41.

[85] Merghati-Khoei E, Pirak A, Yazdkhasti M, et al. Sexuality and elderly with chronic diseases: a review of the existing literature. J Res Med Sci 2016;21:136.

[86] Rao TS. Psychobiology of love and sexual relationships in the elderly: issues in management. J Geriatr Ment Health 2016;3(2):91-9.

[87] Lalitha K. Health aspects of elderly: a global issue. J Krishna Inst Med Sci Univ 2012;1(2):1-3.

[88] De Sousa A. Do Indian social norms curb freedom of our elderly in an old age home? J Geriatr Ment Health 2015;2(2):118-9.

[89] Bhatt AN, Joseph MR, Xavier IA, et al. Health problems and healthcare needs of elderly-community perspective from a rural setting in India. Int J Community Med Public Health 2017;4(4):1213-8. 
[90] Sears JT. Growing older: perspectives on LGBT aging. UK: Routledge 2013.

[91] Preeti Y, Neelma K. Effect of physical exercise and yoga on sexuality of old age persons. Asian J Home Sci 2009;4(1):133-4.

[92] Khosla D, Patel FD, Sharma SC. Palliative care in India: Current progress and future needs. Indian J Palliat Care 2012;18(3):149-54.

[93] Puchalski C, Ferrell B, Virani R, et al. Improving the quality of spiritual care as a dimension of palliative care: The report of the Consensus Conference. J Palliative Med 2009;12(10):885-904.

[94] Cherny NI, Christakis NA. Oxford Textbook of Palliative Medicine. Oxford: Oxford University Press 2011.

[95] Farmer P, Frenk J, Knaul FM, et al. Expansion of cancer care and control in countries of low and middle income: a call to action. Lancet 2010;376(9747):1186-93.

[96] Mallath MK, Taylor DG, Badwe RA, et al. The growing burden of cancer in India: epidemiology and social context. Lancet Oncol 2014;15(6):e205-12.

[97] Elango JK, Sundaram KR, Gangadharan P, et al. Factors affecting oral cancer awareness in a high-risk population in India. Asian Pac J Cancer Prev 2009;10(4):627-30.

[98] Anand A. Exploring the role of socioeconomic factors in abuse and neglect of the elderly population in Maharashtra. J Geriatr Ment Health 2016;3(2):150-7.

[99] Grover S. Elder abuse: the need for awareness. J Geriatr Ment Health 2015;2(2):65-7.

[100] Kaur J, Kaur J, Sujata N. Comparative study on perceived abuse and social neglect among rural and urban geriatric population. Indian J Psychiatry 2015;57(4):375-8.

[101] Saikia AM, Mahanta N, Mahanta A, et al. Prevalence and risk factors of abuse among community dwelling elderly of Guwahati city, Assam. Indian J Community Med 2015;40(4):279-81.

[102] Tripathy JP. Geriatric care in India: a long way to go. J Midlife Health 2014;5(4):205-6.

[103] Kosberg JI, Garcia JL. Elder abuse: International and cross-cultural perspectives. UK: Routledge 2013.

[104] Ettner R. Care of the elderly transgender patient. Curr Opin Endocrinol Diabetes Obes 2013;20(6):580-4.

[105] Harley DA, Teaster PB. Handbook of LGBT elders: an interdisciplinary approach to principles, practices and policies. Berlin: Springer 2015.

[106] Knauer NJ. LGBT elder law: toward equity in aging. Harvard J Law Gender 2009;32:1-3.

[107] Arabelo H, Siddiqi S, Matti-Orozco B. Out and proud to your doctor: The LGBT elderly views about sexual orientation in their doctor's visit. J Am Geriatr Soc 2010;58:S225-S8.

[108] Katiyar RV, Ahmad S. Psychosocial and professional challenges for individual having cleft lip and palate: a case report. Era J Med Res 2019;6(2):173-6.

[109] Ahmad S, Wasim S, Irfan S, et al. Qualitative vs. quantitative research - a summarised review. J Evid Based Med Healthc 2019;6(43):2828-32. DOI: 10.18410/jebmh/2019/587. 